\title{
O Metaprojeto no Desenvolvimento de Modelos de Negócio de Plataforma
}

\author{
Bruno Augusto Lorenz; \\ Carlo Franzato; \\ Gustavo Severo Borba; \\ Karine de Mello Freire
}

resumo:

O presente artigo busca elaborar uma reflexão teórica sobre a relação entre o modelo de negócios de plataforma e o metaprojeto, afim de potencializar o desenvolvimento de plataformas mais éticas, eficazes e inovadoras. Em um primeiro momento, se discute o papel do design como um paradigma de inovação nas organizações contemporâneas, focado na implementação e difusão de uma cultura de projeto que influencia profundamente 0 funcionamento de tais organizações. Tal cultura é essencial para companhias que se veem imersas em sistemas de criação de valor, onde diferentes atores econômicos - fornecedores, parceiros, aliados e consumidores - trabalham juntos na coprodução desse valor. Assim, é primaz para as organizações desempenhar um papel estratégico de reconfiguração das atividades e do relacionamento nessa constelação de atores. Os modelos de negócio de plataforma se apresentam nesse contexto como uma maneira eficaz de articular tais agentes e seus interesses. Na estrutura de plataforma, organizações passam a interagir em uma complexa rede de relações, onde os produtores, consumidores e a própria plataforma passam a desempenhar diferentes papéis, conectando-se e conduzindo interações uns com os outros. No entanto, a partir do momento em que se entende a plataforma como estrutura, é preciso contestar os princípios que embasam sua constituição. O metaprojeto contribui para o debate ao questionar os fundamentos e as bases metodológicas que guiam os preceitos desse modelo de negócio. Quais são os valores que devem ser gerados pela plataforma? De que forma os usuários podem criar e consumir esse valor, utilizando os subsídios oferecidos pela organização? Por meio dessas leituras, é possível identificar três temas que liga as plataformas ao metaprojeto: o deslocamento de níveis, projetar para abraçar a colaboração e a abertura para a emergência. Dar foco nesses três princípios nos processos de projeto potencializa o desenvolvimento de plataformas eficazes na produção de valor e direcionadas pela ética e pela inovação.

palavras-chave:

Plataformas; Metaprojeto; Design Estratégico; Modelos de Negócio 


\section{Introdução}

Estudar o contexto de um cenário globalizado e de constante transformação exige reflexões sobre pelo menos dois temas: a complexidade e a inovação. Viver nesse paradigma significa aceitar a incerteza e abraçar a ideia de que nem todo o conhecimento humano dá conta de definir e entender todas as dimensões da realidade e as relações que nela existem. Rafael Cardoso (2012, p. 23) defende que "no mundo complexo em que vivemos, as melhores soluções costumam vir do trabalho em equipe e em redes". Insistir no desenvolvimento dos mesmos produtos e serviços não é mais o bastante para se manter ativo nos competitivos e globalizados mercados atuais. Essa nova realidade demanda inovações focadas na criação de experiências e no desenvolvimento de inovações disruptivas: sistemas que revolucionam mercados existentes, substituindo cadeias ineficientes por outras mais convenientes, acessíveis e baratas (MURATOWSKI, 2015). Esse raciocínio reflete um cenário onde organizações precisam adotar estratégias de adaptação contínua e o consumidor não mais interpreta um papel passivo nos processos de desenvolvimento de novos produtos e serviços, mas tem, inclusive, o poder de influenciar os rumos que esses projetos podem tomar.

Lidar com esse cenário significa adotar uma estratégia de co-criação que se beneficia da "criatividade social" e da competência dos diferentes atores envolvidos na rede, tornando assim o processo de design uma atividade participativa e colaborativa (MERONI, 2008). O princípio básico da abordagem denominada de co-design é a participação de todos aqueles envolvidos no problema, seja concebendo ou implementando soluções. As necessidades dos usuários, bem como seus comportamentos, não podem ser previstos nas etapas de projeto devido a inconstância desses parâmetros. É necessário, portanto, que os usuários sejam incluídos e estejam engajados no processo de formulação e resolução de problemas enquanto o sistema é desenvolvido e quando esse sistema for utilizado (GIACCARDI, 2005). O papel do designer nesse contexto se desloca então para o de um agente estratégico e não mais de "mero" executor. Ao considerar que designers não são os únicos agraciados com a capacidade criativa e que todos são capazes de criar e projetar, cabe ao designer pensar estrategicamente e entender como o projeto pode se beneficiar dessa capacidade coletiva de criação, desenvolvendo um senso de envolvimento, ativação, troca de ideias e bem estar entre todos os envolvidos na atividade projetual (MERONI, 2008).

Recentemente, organizações de naturezas diversas, incluindo instituições financeiras, bancos e consultorias de gestão começam a adotar o design como princípio guia, ao construir competências internas de projeto (MURATOWSKI, 2015). Para Franzato e Celaschi (2012) "nas empresas de alto envolvimento com o design, que incorporam a cultura de projeto no cerne da organização, o design é considerado um paradigma de inovação". Além disso, tais organizações gradativamente passam a compreender também como co-criação é necessária para sua sobrevivência no contexto em que estão inseridas. É necessário, então, que suas estratégias deem conta de abraçar iniciativas que envolvam colaboradores, fornecedores e clientes no processo de desenvolvimento de novos produtos e serviços. O design estratégico possui um papel fundamental nesse processo através da implementação de uma cultura de projeto que influencia profundamente o funcionamento dessas organizações. Para Zurlo (2010) "O design, por sua natureza, sabe interpretar a complexidade, capturando dela estruturas de sentido; sabe indicar um caminho, tornando-o visível; e sabe comunicar e gerir os processos de compartilhamento das escolhas dentro da organização".

Zurlo (2010) destaca o papel do design estratégico na condução desse processo ao defini-lo como uma atividade que se relaciona com a formulação e o desenvolvimento das estratégias de uma organização. Essa estratégia tem por objetivo a construção de um conjunto coerente e funcional de diferentes atividades em que a empresa baseia sua identidade e se posiciona frente ao mercado e a sociedade. O design estratégico tem como premissas a articulação entre os diversos atores envolvidos no projeto através da gestão dos trabalhos em equipe, da facilidade em falar a linguagem tanto de técnicos e gestores, orientação para a resolução rápida e metodológica dos problemas além de saber governar situações complexas. Entender o contexto e o ambiente em que está inserida é primordial para um posicionamento estratégico eficaz. É preciso considerar que essas estratégias só darão resultados a partir do entendimento da complexa cadeia de atores envolvidos na criação de valor e que essa não 
acontece apenas no âmbito da organização. Ela depende de todas as relações existentes entre os agentes dessa cadeia.

Para Normann e Ramírez (1993), estratégia é criação de valor, sendo ela a provedora de frameworks intelectuais, modelos conceituais e ideias que direcionam a empresa na identificação e na execução de atividades que entregam valor aos seus consumidores. Cada vez mais, companhias se veem imersas em sistemas de criação de valor, onde diferentes atores econômicos - fornecedores, parceiros, aliados e consumidores - trabalham juntos na coprodução desse valor. Dessa forma, organizações precisam desempenhar um papel estratégico de reconfiguração das atividades e do relacionamento nessa constelação de atores, com o objetivo de mobilizar a criação de valor de novas formas e por novos atores, assegurando que a inovação irá, de forma sustentável, entregar o valor pretendido para todos os membros que fazem parte da rede (NORMANN; RAMÍREZ, 1993; OUDEN, 2012).

Muratowski (2015) explica que, uma vez que a competição dos mercados globalizados se acirrava, sistemas produtivos inteiros foram deslocados e terceirizados em companhias orientais, o que barateava os custos e padronizava a produção para atender as demandas de mercados massificados. Entretanto, apesar dos benefícios financeiros dessas empreitadas, ficaram visíveis também inúmeras desvantagens sociais e ecológicas associadas a esses modelos de manufatura. A falta de regulações e a falta de preocupação por problemas ambientais causaram níveis alarmantes de poluição e desperdício nas economias emergentes que recebiam essas indústrias (MURATOWSKI, 2015). Para Ouden (2012), a inovação é uma das principais vias pelas quais desenvolvem-se soluções para enfrentar essa série de problemas complexos que desafiam a sociedade contemporânea. Todavia, é crescente o entendimento de que esses desafios só podem ser confrontados por meio de um esforço conjunto e colaborativo de empresas, organizações, governos e cidadãos.

Ouden (2012) acredita que a partir da geração de valor proveniente desses esforços, a sociedade se beneficiará como um todo. Para melhor compreensão do conceito "valor", é importante entender em qual nível ele é percebido. A partir daí, a autora desenvolve um framework que apresenta quatro diferentes níveis de valor no contexto da inovação: o nível do usuário, da organização, do ecossistema e da sociedade. Esses níveis se sobrepõem e interagem entre si: os valores do usuário precisam ser incluídos no valor para as empresas, que por sua vez precisam estar no contexto do ecossistema e este último, por fim, precisa estar inserido no nível da sociedade (OUDEN, 2012). A figura 1 apresenta a estrutura do framework:

Figura 1 - Framework de valor de Ouden

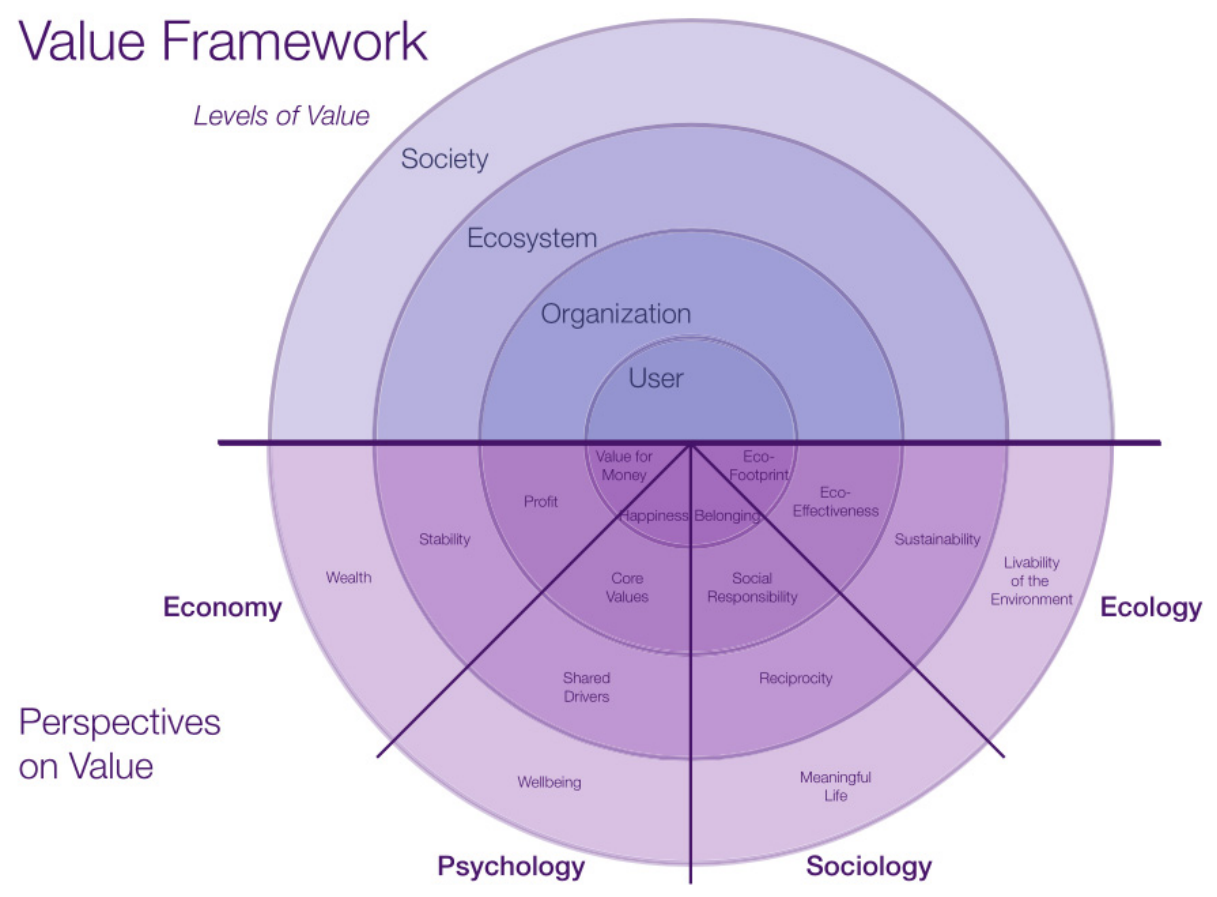

Fonte: Ouden (2012). 
É primaz, contudo, que se questione sobre a definição do termo valor: o que ele considera? Como ele é entendido pelos diversos agentes que fazem parte do sistema? Quais são as dinâmicas que direcionam a sua criação? A abordagem metaprojetual — ligada ao design estratégico — responde a essas questões ao prover "uma reflexão acerca do projeto em desenvolvimento, paralela e para além dele, o que fundamenta e justifica o projeto em si, em relação ao contexto que o originou e em relação ao cenário para o qual é destinado" (FRANZATO; CELASCHI, 2012, p. 2). Para os mesmos autores, o metaprojeto estimula ainda uma reflexão posterior, concentrada na conscientização dos envolvidos sobre os significados do projeto. Giaccardi (2005), compreende o metaprojeto como o projeto de ferramentas, parâmetros e condições de operação que permitem uma flexibilidade infinita na formatação de um produto industrial. $\mathrm{O}$ metadesign preocupa-se, não apenas com objetos e conteúdos, mas principalmente com métodos e estruturas fluídas que operacionalizam o processo de design.

Ao refletir sobre o contexto apresentado até o momento, é possível questionar sobre modelos de negócios que possam dar conta das necessidades de adaptação constante, de geração de valor para todos os níveis trazidos por Ouden (2012) e que respondam aos ecossistemas de inovação, operando em redes e se conectando aos diversos atores envolvidos para geração de inovação, valor e conhecimento. No presente artigo, considera-se que o modelo de plataforma apresenta características que respondem a todas as questões levantadas.

Parker, Alstyne e Choudary (2016) descrevem plataformas como modelos de negócios que se utilizam da tecnologia para conectar pessoas, organizações e recursos em um ecossistema interativo, que possibilita a criação e a troca de valor entre produtores e consumidores externos. A plataforma provê uma infraestrutura participativa e aberta para que ocorram essas interações e desenvolve as condições para que elas ocorram. Um dos objetivos mais abrangentes da plataforma é o de permitir, além da criação de valor para todos os participantes da mesma, facilitar a troca de bens, serviços e de moedas sociais entre seus usuários (PARKER; ALSTYNE; CHOUDARY, 2016). A partir do momento em que se entende que as plataformas se desenvolvem a partir de regras pré-estabelecidas de funcionamento, mas que, ao mesmo tempo, esse sistema precisa se manter aberto para que os usuários da plataforma possam agir para que ela evolua e melhore ao longo do tempo, é possível sugerir uma estreita ligação com o metaprojeto - e, por consequência, com o design estratégico.

Posto isso, o presente artigo busca elaborar uma reflexão teórica sobre a relação existente entre o conceito de plataforma e o metaprojeto. Em um primeiro momento, o artigo busca analisar o que define uma plataforma, quais suas características e finalidades e quais são ligações e influências do design estratégico junto a esse modelo de negócios, dando atenção especial ao conceito de valor que permeia esses temas. Posteriormente, propõe-se analisar as plataformas sob a ótica do metaprojeto: o que se entende, quais suas relações e como o designer pode projetar uma plataforma que amplifique sua capacidade de funcionamento e de desenvolvimento a partir da geração de valor entre aqueles que fazem uso da mesma.

\section{Plataformas e sua relação com o Design Estratégico}

Plataformas são novos modelos de negócios que se tornaram possíveis e passaram a fazer sentido a partir da popularização da internet e das mudanças acarretadas por ela. Choudary (2015) argumenta que modelos lineares foram os modelos de negócios predominantes na economia industrial, produzindo e entregando o valor "em linha reta". Nessa forma de se organizar, as funções de produção e consumo estão claramente demarcadas, localizando o usuário no fim dessa cadeia e conferindo-lhe apenas um papel de consumidor passivo. Três fatores, contudo, estão contribuindo para uma mudança de paradigma: a crescente conectividade, a produção descentralizada e a evolução da inteligência artificial (CHOUDARY, 2015).

Segundo Parker, Alstyne e Choudary (2016), a plataforma é um novo modelo de negócios que recorre a tais fatores e foca no desenvolvimento tecnológico para conectar pessoas, organizações e recursos em um ecossistema interativo, que sobrevive e se adapta mediante a criação e troca de valor. Um número cada vez maior de organizações está saindo de uma estrutura linear para uma estrutura de plataforma, passando a interagir em uma complexa rede de relações onde os produtores, consumidores e a própria plataforma passam a desempenhar diferentes papéis, se conectando e conduzindo interações uns com os outros. $\mathrm{O}$ 
valor é co-criado, trocado, alterado e consumido em uma variedade de formas e lugares - tudo possibilitado pelos recursos e facilidades oferecidos pelas plataformas (CHOUDARY, 2015; PARKER; ALSTYNE; CHOUDARY, 2016).

O potencial disruptivo das plataformas é tamanho que, boa parte das grandes empresas que surgiram nas últimas duas décadas e que hoje figuram como impérios econômicos bilionários, adotaram esse modelo de negócios. Independente de particularidades específicas de cada uma, Google, Facebook, Apple, Amazon, Uber, Airbnb são algumas das empresas que se utilizam do modelo de plataformas para crescer rapidamente a partir das interações e trocas que ocorrem em seus ecossistemas. No quadro 1, é possível identificar algumas das características que diferenciam ambos os modelos:

Quadro 1 - Diferenças entre o modelo linear e o modelo de plataforma

\begin{tabular}{|l|l|l|}
\hline Característica & Modelo Linear & Modelo de Plataforma \\
\hline $\begin{array}{l}\text { Relação com } \\
\text { intermediários }\end{array}$ & $\begin{array}{l}\text { Baseiam seus modelos de negócios em } \\
\text { intermediários }\end{array}$ & $\begin{array}{l}\text { Remove interlocutores do processo e } \\
\text { escalam de forma mais eficiente }\end{array}$ \\
\hline $\begin{array}{l}\text { Investimentos para } \\
\text { atingir escala }\end{array}$ & $\begin{array}{l}\text { Para crescer, precisam investir recursos } \\
\text { financeiros para compra e manutenção de } \\
\text { bens físicos. }\end{array}$ & $\begin{array}{l}\text { Desenvolvem novas fontes de valor e } \\
\text { suprimentos sem precisar investir } \\
\text { grandes quantidades de dinheiro e } \\
\text { administrar ativos físicos }\end{array}$ \\
\hline $\begin{array}{l}\text { Aprimoramento dos } \\
\text { produtos e garantia } \\
\text { de qualidade }\end{array}$ & $\begin{array}{l}\text { Para assegurar a qualidade dos produtos e } \\
\text { serviços e para definir as interações com } \\
\text { o mercado, se baseiam em mecanismos } \\
\text { de controle - editores, supervisores e } \\
\text { gerentes - acarretando custos. }\end{array}$ & $\begin{array}{l}\text { Confiam em sistemas e ferramentas } \\
\text { que se desenvolvem e se aprimoram a } \\
\text { partir do feedback contínuo e circular. }\end{array}$ \\
\hline $\begin{array}{l}\text { Foco em recursos } \\
\text { internos e externos }\end{array}$ & $\begin{array}{l}\text { Baseado no modelo tradicional, foca nas } \\
\text { atividades internas da empresa: } \\
\text { otimização dos processos e dos produtos, } \\
\text { controle dos empregados, controle de } \\
\text { estoques e construção de barreiras contra } \\
\text { os competidores. }\end{array}$ & $\begin{array}{l}\text { Tendo em vista que o valor criado na } \\
\text { plataforma vem da comunidade de } \\
\text { usuários, o foco primário muda das } \\
\text { atividades internas para as externas. É } \\
\text { um processo de empresa invertida: } \\
\text { operações e estratégias são centradas } \\
\text { em pessoas, ativos e funções que } \\
\text { existem fora dela. }\end{array}$ \\
\hline
\end{tabular}

Fonte: elaborado pelo autor, adaptado de Parker, Alstyne e Choudary (2016).

Como já enfatizado ao longo do texto, um dos pilares que sustentam as plataformas como modelos de negócio é a constante troca e geração de valor que acontece através dela. Entender o conceito de "valor" sob diferentes pontos de vista é essencial para compreender a relação entre design estratégico e as plataformas.

Mauri (1996, p. 9) associa valor ao sistema de consumo e a processos de criação de sentido: "[...] dou valor ao objeto quando este me comunica alguma coisa, que se inscreve na ordem dos meus valores e do meu "sentir" [...] para uma reedição atualizada da minha identidade pessoal e cultural". Zurlo (2010) se alinha a esse raciocínio quando afirma que, ao operar em âmbitos coletivos, o design estratégico busca gerar efeitos de sentido - ou seja, a dimensão de valor para alguém - através da ação e do desenvolvimento de Sistemas ProdutoServiço que se configuram como uma materialização da própria estratégia de uma organização. Esses sistemas precisam se organizar de forma consistente e integrada, para que respondam de forma satisfatória às necessidades e demandas de seus consumidores em diferentes contextos (MERONI, 2008).

Ao se aproveitar da capacidade exponencial de escala e alcance proporcionados pela internet, os modelos baseados em plataforma podem atingir indivíduos e mercados localizados em diferentes partes do mundo. Tais negócios têm potencial de acarretar sociais em grandes escalas, considerando que elas permitem que pessoas possam criar novas fontes de renda oferecendo produtos e serviços que não seriam possíveis de serem ofertados sem o suporte da plataforma - alugando seus quartos e casas no Airbnb, por exemplo (SAMPERE, 2016). Com 
tamanho poder, é importante analisar o impacto desse modelo de negócios nos quatro níveis de valor apresentados por Ouden (2012), entendendo assim quais os efeitos das plataformas em relação a indivíduos, empresas, ecossistemas e na sociedade.

Ouden (2012) entende que o alvo máximo da inovação é aquele que acontece no nível de usuário, já que será ele que utilizará o sistema, seja um produto ou um serviço. Valor para o usuário é aquilo que atende suas necessidades, sejam elas físicas, psicológicas ou sociais. Jacob e Rodriguez (2008), defendem que o comportamento inovador das empresas pode surgir a partir de um viés tecnológico ou dos negócios, mas que o sucesso de suas iniciativas depende da capacidade de elencar como foco principal a preocupação com as necessidades humanas. Uma proposta que não tenha o usuário como parte central da sua construção, corre o risco de cair na irrelevância e, como consequência, ser incapaz de influenciar os outros níveis (OUDEN, 2012). Com relação às plataformas, essa premissa se mostra pertinente, visto elas dependem exclusivamente das trocas feitas por seus usuários para existir e se manterem ativas. Choudary (2015) observa que nas plataformas, não são as empresas que criam o valor: elas apenas permitem a criação dele. Dessa forma, os participantes tomam para si tanto o papel de produtores quanto de consumidores.

O segundo nível apresentado por Ouden (2012) é o da organização, onde a autora entende que a geração de valor acontece justamente quando esse empreendimento consegue gerar valor para seus consumidores e, como consequência, garantir sua existência. Essas propostas podem surgir de duas perspectivas distintas: através de lideranças de direção e gerência - caracterizando uma cultura do topo para a base - ou a partir de uma cultura em que todos os colaboradores entendam seu papel e possam propor e organizar iniciativas - uma cultura da base para o topo. Para que uma inovação desse último tipo floresça, é primaz a necessidade de um ambiente em que se encoraje o desenvolvimento da criatividade em todos os níveis da organização - elemento chave em toda cultura de inovação (OUDEN, 2012; DESERTI; RIZZO, 2014). Uma plataforma bem sucedida cria combinações entre os usuários certos para que os bens e serviços mais relevantes sejam trocados. Essa dinâmica é alcançada e constantemente otimizada a partir do uso das informações coletadas pelo sistema através das tecnologias empregadas no sistema. Quanto maior a capacidade da plataforma de coletar, organizar e interpretar os dados, maiores são chances de aprendizado, resultando em melhorias que geram valor tanto para plataforma quanto para seus usuários (PARKER; ALSTYNE; CHOUDARY, 2016). Ou seja: as mudanças e o desenvolvimento dessas melhorias ocorre a partir da interação de processos de inovação da base para o topo e do topo para a base.

Para criar infraestruturas que facilitem a criação e a troca de valor, as organizações precisam definir os princípios que governam essas iterações. É importante destacar o papel da inteligência artificial nesses processos, visto que toda a captura dos dados é feita a partir dos algoritmos que formam a plataforma. Não se deve ignorar, contudo, a contribuição dos designers nesse processo, que precisam interpretar essa massa de dados capturada pelo algoritmo e dar sentido a ela a partir de ações que promovam a melhoria da plataforma. Neste contexto, colaboram as capacidades específicas do design identificadas por Zurlo (2010) — ver (capacidade de leitura orientada dos contextos e sistemas), prever (capacidade de antecipação crítica do futuro) e fazer ver (capacidade de visualizar cenários futuros e torná-los visíveis a terceiros).

Com relação ao nível de ecossistema, Ouden $(2012$, p. 17) entende que este inclui "todos os stakeholders que têm papéis diretos ou indiretos durante as várias fases do processo de inovação: definição, criação, realização e extensão". Esses agentes criam redes de negócios, que geram um valor maior do que organizações sozinhas seriam capazes de alcançar. (OUDEN, 2012) O potencial das plataformas se mostra presente neste nível devido a sua capilaridade. Ao alcançar atores que vivem em diferentes contextos e territórios, abre-se a possibilidade de que estes tragam para a plataforma conhecimentos, aprendizados e habilidades que beneficia a plataforma como um todo. Exemplos disso podem ser encontrados nos ecossistemas de aplicativos para celulares, como o Android (da Google) e o iOS (da Apple). Ambas as companhias permitem que desenvolvedores externos de todas as partes do mundo - de empresas de tecnologias a estudantes de design e programação — criem aplicativos que podem ser adquiridos pelos consumidores que utilizam seus smartphones. Dessa forma, todos os agentes envolvidos na dinâmica desse ecossistema - a plataforma, os produtores e os consumidores do aplicativo - se beneficiam das inovações, ideias e dos valores criados no processo. Verganti 
(2009) dá suporte teórico a essa dinâmica, ao explicar que as organizações voltadas a inovação estão imersas em um laboratório de pesquisa coletiva que compreende empresas, designers, artistas e universidades - cada um desenvolvendo suas próprias pesquisas. Esses pesquisadores, contudo, compartilham ideias, interpretações e propostas na forma de estudos, discursos e produtos que beneficiam todos ligados a essa rede.

Por fim, ao discutir o último dos níveis, Ouden aborda o impacto de inovações na sociedade através de um exemplo trazido por Lester Brown (apud OUDEN, 2012), que alerta para os custos invisíveis pagos pela sociedade por um trivial galão de gasolina. Ao considerar apenas o preço nas bombas dos postos, ignora-se os gastos públicos para tratamento de doenças respiratórias causadas pela queima dos combustíveis fósseis, por exemplo. Desse ponto de vista, entende-se que os cidadãos sempre são stakeholders de qualquer inovação na sociedade. Manifestações das plataformas nesse nível de valor podem ser acompanhadas a partir dos impactos causados pela chegada do Uber no Brasil, por exemplo. A partir do momento que empresa apresenta uma nova dinâmica nos serviços de transporte, diferentes setores da sociedade são afetados das mais diversas maneiras: taxistas sentem a diminuição do números de passageiros e em seus lucros; ${ }^{1}$ o poder público é cobrado a tomar providências em relação a implementação de regulações no serviço; ${ }^{2}$ consumidores mudam seus hábitos e os concorrentes do serviço buscam responder a essas mudanças. ${ }^{3}$

Nesse sentido, é possível identificar a grande responsabilidade daqueles envolvidos na construção de plataformas e na previsão dos impactos que ela pode causar a partir do momento que ela entra em funcionamento. Para que esses projetos sejam construídos de maneira eficaz e preocupada com a ética, o metaprojeto precisa estar presente neste processo.

\section{Metaprojeto}

Para discutir metaprojeto, é necessário retomar o conceito de complexidade. Vassão (2010, p. 13) expõe seu entendimento sobre o termo ao afirmar que "complexo é um conjunto de coisas simples, percebidas como algo complexo apenas pela acumulação de simplicidades muito numerosas", e complementa este raciocínio quando explica que a compreensão do metaprojeto se dá quando entende-se a lógica que busca assimilar a complexidade, ao torná-la um conjunto de objetos simples e de fácil entendimento (VASSÃO, 2010). Argumenta o autor:

[...] parte do Metadesign é reconhecer como a realidade, enquanto representação de um mundo que provavelmente estará sempre além de nossa compreensão absoluta, é um objeto de trabalho, uma obra individual e/ou coletiva, e que, quando ela torna-se coletiva, é ainda outro processo de construção de uma realidade comungada (VASSÃO, 2010, p. 16).

No entendimento de Vassão, o metaprojeto se aproveita da complexidade para alcançar possibilidades generativas, abertas e colaborativas ao considerar o próprio projeto como objeto de design. Bentz e Franzato (2016) compartilham visão semelhante, quando argumentam que o metaprojeto preocupa-se com o transitório, o provisório e o imutável e "interessa-se pela inapreensível possibilidade de vir a ser, não pelos possíveis estados tangíveis do ser". Está identificado, portanto, como um sistema que sustenta e beneficia o projeto (BENTZ; FRANZATO, 2016, p. 13).

Entender o design como matéria de projeto acarreta reflexões que abordam uma retomada crítica do ato criativo e das práticas projetuais. "O metadesign deve mudar de nível, deve passar do nível onde o design age para um nível que transcende esse fazer, de onde o metadesign possa agir sobre o design" (FRANZATO, 2014, p. 3). Ao considerar os argumentos

\footnotetext{
${ }^{1}$ ARAÚJO, G. Após UberX, taxistas têm de trabalhar até 6h a mais para manter ganhos. G1, São Paulo. Disponível em: <http://g1.globo.com/sao-paulo/noticia/2016/07/apos-uberx-taxistas-tem-de-trabalhar-ate6h-mais-para-manter-ganhos.html>. Acesso em: 26. jun. 2017.

2 JUSTINO, G. Prefeitura entrega à Câmara projeto de regulamentação do Uber. ZH, Porto Alegre. Disponível em: $<$ http://zh.clicrbs.com.br/rs/porto-alegre/noticia/2016/05/prefeitura-entrega-a-camaraprojeto-de-regulamentacao-do-uber-5802483.html>. Acesso em: 26 jun. 2017.

${ }^{3}$ ARAÚJO, G; GOMES, H. S.; DOMINGOS, R. São Paulo na era Uber. G1, São Paulo. Disponível em: $<$ http://especiais.g1.globo.com/sao-paulo/2016/especial-uber/>. Acesso em: 26 jun. 2017.
} 
de Van Onck (1965) - pioneiro nas reflexões sobre o tema no país —, Franzato (2014) aponta que o principal princípio metodológico que ele propõe é o deslocamento de nível. O que muda do design para o metaprojeto nesse sentido não é natureza projetual do processo, mas nível e matéria da ação projetual, o que encadeia mudanças também no seu resultado. "[...] o princípio do deslocamento prevê a mudança de nível do ponto de vista do designer e o desenvolvimento de processos projetuais paralelos e para além dos que ele já desenvolvia" (FRANZATO, 2014, p. 2).

O deslocamento de nível no metaprojeto impacta os resultados da atividade projetual quando reflete sobre os níveis de conhecimento e entende que os movimentos encadeados e comprometidos que existem nessa dinâmica materializam e afetam o processo projetual em si (BENTZ; FRANZATO, 2016). Afirmam os autores:

Em termos específicos de design, os processos projetuais estão em nível diferente daquele em que o designer age. É o que prevê o princípio do deslocamento, que entende os processos criativos como resultantes de práticas metaprojetuais. Nessa perspectiva, todos os processos são crítico-reflexivos e heurísticos, capazes de responder à complexidade do pensamento e da produção cultural humana (BENTZ; FRANZATO, p. 2).

Dada a sua natureza, o metaprojeto torna-se essencial para o desenvolvimento de qualquer ação projetual que vise questionar criticamente seus processos e possibilidades de vir a ser de seus resultados. Franzato (2014) observa, no entanto, que o metaprojeto - ao ser entendido como abordagem metodológica — não se limita a procedimentos projetuais específicos, tendo em vista a inexistência de uma sequência de passos predeterminada que permita evoluir um processo de metaprojeto.

O deslocamento de níveis é um dos princípios do metadesign que vai de encontro com preceitos das plataformas. Parker, Alstyne e Choudary (2016) apontam que designers que se deparam com a tarefa de desenvolver plataformas geralmente percebem uma grande dificuldade de identificar um ponto de partida para a empreitada, dada a natureza inerentemente complexa dos sistemas que enfrentam. A tendência natural é que eles analisem e estudem e copiem projetos similares. O problema, defendem os autores, reside no fato de que não existem dois mercados idênticos, o que acaba resultando em falhas estratégicas, que não produzem valor para seus usuários nem geram nenhum tipo de efeitos no ecossistema.

Nesse sentido, o metaprojeto beneficia o desenvolvimento de uma plataforma ao questionar seus fundamentos e as bases metodológicas que guiam os preceitos desse modelo de negócio. Quais são os valores que devem ser gerados pela plataforma? De que forma os usuários podem criar e consumir esse valor, utilizando os subsídios oferecidos pela organização? Em que se baseiam os princípios éticos que guiam as dinâmicas dessas iniciativas e como elas se refletem no desenho final da plataforma? Nesse sentido o "metaprojeto é especialmente apropriado para o desenvolvimento de processos empresariais orientados a re-pensar radicalmente a atuação de uma organização, a definir as suas estratégias futuras e a inová-las" (FRANZATO; CELASCHI, 2012, p. 2).

Essas variadas dinâmicas do metaprojeto apontam também para características que facilitam a colaboração entre diversos agentes no processo de design e na busca por inovação. Ao promover práticas colaborativas de projeto, o metaprojeto se desenvolve em direção a novas formas de compreensão e de planejamento, com o objetivo de desenvolver sistemas de interação mais abertos e acolhedores (GIACCARDI, 2005). Para a mesma autora, o metaprojeto abre a possibilidade de que os usuários possam agir de forma criativa como designers, fornecendo ambientes e novas mídias dotadas de suportes sociais e técnicos que tenham a intenção de empoderar esses usuários como os verdadeiros "donos dos problemas".

De Mul (2011) concorda com Giaccardi, ao especular sobre o papel do designer nesse processo. $\mathrm{O}$ autor acredita que o designer do futuro deve se tornar um meta-designer, preocupando-se não mais com o desenho de objetos, mas na construção de espaços de projeto onde usuários sem nenhuma experiência de projeto se sintam capazes por esse ambiente a desenhar os seus próprios artefatos. Franzato $(2014$, p. 7) contribui com essa visão ao declarar que o "metadesign é entendido como um processo de design ulterior, voltado para determinar as lógicas do processo de design", possibilitando assim o desenvolvimento de sistemas e ambientes 
onde uma série de agentes podem ser responsáveis pelo projeto: desde os próprios "metadesigners", passando por outros designers, usuários sem habilidades projetuais e até mesmo máquinas.

É possível identificar, portanto, o segundo princípio do metaprojeto que se alinha com as necessidades e dinâmicas das plataformas. Uma das principais características desse modelo de negócios é a necessidade da interação entre dois grupos distintos (produtores e consumidores). Sem um número suficiente de usuários em qualquer um dos lados, a plataforma deixa de ter valor (TIWANA, 2014). Para Parker, Alstyne e Choudary (2016), a plataforma deve prover uma infraestrutura robusta para que as interações entre esses grupos ocorram, ao mesmo tempo que ela precisa ser participativa e aberta para que os usuários interajam e criem valor de maneiras que não haviam sido pensadas inicialmente. Esses comportamentos imprevistos servem como combustível para o desenvolvimento de funcionalidades e para o aprimoramento da plataforma. Franzato e Celaschi (2012) observam que um dos principais benefícios do metaprojeto é "o aprendizado que a empresa desenvolve sobre si mesma", visto que esse aprendizado sobre os contextos em que está inserida indicam novos cenários e trajetórias de inovação que podem ser seguidas.

As perspectivas da co-criação e colaboração abertas pelo metaprojeto carregam consigo características que sugerem uma aproximação com temas do paradigma da complexidade, como o provisório e o imutável. O foco do metaprojeto em uma integração bem sucedida das metodologias de design pela antecipação, participação e emergência se traduz na identificação de um espaço de projeto multidimensional (GIACCARDI, 2005, p. 347). Deserti e Rizzo (2014) destacam que que uma série de estudos consideram mudança como algo emergente ao invés de planejado. Fatores externos - economia, comportamento dos competidores, clima político - e internos - incerteza, distribuição de conhecimento - influenciam também a mudança dos direcionamentos. Até mesmo os mais cuidadosos planejamentos e programas de execução possuem qualidades e feitos emergentes (DESERTI; RIZZO, 2014).

Os processos de metaprojeto atuam diretamente nessa abordagem que suporta a incerteza e a fluidez quando se entende o design não mais como uma atividade de planejamento, mas de "semeadura" (GIACCARDI, 2005). Nesse sentido, o projeto buscar aceitar uma dinâmica com menor controle das variáveis, que se abre para possibilidades inimagináveis desde o seu surgimento. Essa abertura para a emergência é outro dos princípios do metaprojeto que se alinham com o comportamento das plataformas. Parker, Alstyne e Choudary (2016) defendem que é necessária máxima atenção aos princípios de projeto da plataforma para que ela maximize as chances de criação de valor. Entretanto, uma das principais características desse modelo de negócio - o controle das atividades pelos usuários - faz com que a causalidade tenha um papel importante no processo, ao permitir com que esses atores interagem de maneiras não planejadas. Os designers que desenvolvem essas plataformas devem deixar espaços para que descobertas casuais reveladas a partir da observação do comportamento dos usuários indiquem para onde o projeto deve evoluir.

\section{Considerações Finais}

Ao estabelecer as relações entre o modelo das plataformas e o design estratégico a partir do metaprojeto, foi possível encontrar três princípios metaprojetuais que impactam de maneira significativa um projeto de design das plataformas: o deslocamento de níveis, o foco na colaboração e a atitude de abertura para a emergência.

Entende-se a importância do princípio do deslocamento de níveis ao retomar a discussão dos níveis de valor de Ouden (2012), onde é necessário refletir sobre os impactos que empreendimentos como plataformas podem trazer a sociedade. A partir do momento que esses modelos de negócios lidam com um grande número de pessoas, invoca-se todos os aspectos éticos, sociais e ambientais que tal iniciativa pode abranger. A discussão dos níveis de deslocamento é pertinente por se preocupar com os aspectos que guiam a atividade projetual que define os princípios desse modelo de negócio.

Com relação ao princípio da colaboração, cabe ressaltar a importância do design como um tradutor das necessidades latentes dos usuários da plataforma, capaz de interpretar os dados adquiridos ao longo das interações. Entende-se que parte da responsabilidade nesse princípio se concentra nos algoritmos utilizados no desenho da plataforma, que registram a dinâmica das 
interações que ocorrem na mesma. Ao retomar as observações de Franzato (2014) e considerando o desenvolvimento da inteligência artificial, é possível sugerir um futuro onde a própria plataforma consiga constantemente se desenvolver para otimizar o seu funcionamento uma máquina que entende os conceitos da plataforma para projetar. Esse cenário, é importante ressaltar, perpassa pelas escolhas projetuais daquelas que desenham a plataforma e conversa com o princípio discutido acima.

Com relação ao princípio da abertura para a emergência, é preciso tomar consciência que lidar com a complexidade nesse contexto não é mais uma vantagem competitiva: é uma necessidade. Ao abraçar o transitório, a incerteza e a pluralidade, as plataformas se mostram mais preparadas que modelos de negócio lineares no que diz respeito a sobrevivência em mercados agressivos e globalizados.

Sob determinados aspectos, confundir o princípio da emergência com o princípio da colaboração parece inevitável. É importante esclarecer, no entanto, que o enfoque do primeiro está na participação dos usuários - e até mesmo dos algoritmos - nos processos de evolução da plataforma, enquanto o segundo abrange interações feitas não só entre os usuários, mas também por todas as outras ligações externas relacionadas ao contexto em que a plataforma está inserida, conforme visto nos estudos de Normann e Ramírez (1993).

\section{Metadesign in the Development of Platform Business Models}

Abstract: The following paper seeks to elaborate a theoretical reflection regarding the relation between Platform Business Models and the metadesign, in order to enhance the development of more ethical, effective and innovative platforms. At first, the role of design as an innovation paradigma in contemporary organizations is discussed, focusing on the implementations and diffusion of a culture Project which deeply influences the functioning of such organizations. This culture is essential to companies which see themselves immersed in value creation systems, where different economical factors - suppliers, partners, allies and consumers - work together to co-produce this value. Therefore, it is paramount for organizations to play a strategic role of reconfiguration of activities and relationships in this constellation of actors. The platform business models presents themselves in this contexto as an effective way of articulating such agents and their interests. In the platform structure, organizations begin to Interact in a complex network of relationships where producers, consumers and the platform itself come to play different roles, connecting and conducting interactions with one another. However, from the moment the platform is understood as a structure, it is necessary to challenge the principles that support its constitution. The metadesign contributes to the debate by questioning the fundamentals and the methodological bases which guide the precepts of this business model. What are the values which should be generated by the platform? How can users create and consume this value using the subsidies offered by the organization? Through these readings, it is possible to identify three main themes that link the platforms to the metadesign: shifting levels, designing to embrace the collaboration and opening for emergency. Focusing on these three principles in project processes potentiates the development of effective platforms for the production of value guided by ethics and innovation.

Keywords: Platforms; Metadesign; Strategic Design; Business Models 


\section{Referências Bibliográficas}

ARAÚJO, G. Após UberX, taxistas têm de trabalhar até $6 \mathrm{~h}$ a mais para manter ganhos. G1, São Paulo. Disponível em: <http://g1.globo.com/sao-paulo/noticia/2016/07/apos-uberx-taxistastem-de-trabalhar-ate-6h-mais-para-manter-ganhos.html>. Acesso em: 26. jun. 2017.

ARAÚJO, G; GOMES, H. S.; DOMINGOS, R. São Paulo na era Uber. G1, São Paulo. Disponível em: <http://especiais.g1.globo.com/sao-paulo/2016/especial-uber/>. Acesso em: 26 jun. 2017.

BENTZ, I; FRANZATO, C. O Princípio do deslocamento: processos e níveis. Working paper, 2016.

CARDOSO, R. Design para um mundo complexo. São Paulo: Cosac Naify, 2012

CHOUDARY, S. Platform Scale: How an emerging business model helps startups build large empires with minimum investment. [S.I., 2015].

DE MUL, J. Redesigning design. In: VAN ABEL, Bas et al. (org.). Open Design Now: Why Design Cannot Remain Exclusive. Amsterdam: BIS publishers, 2011.

DESERTI, A.; RIZZO, F. Design and the Cultures of Enterprises. Design Issues, v. 30, n. 1, p. 36-56, 2014.

FRANZATO, C. O princípio de deslocamento na base do metadesign. In: CONGRESSO BRASILEIRO DE PESQUISA E DESENVOLVIMENTO EM DESIGN, 11., 2014, Gramado. Anais... São Paulo:Editora Edgard Blücher, 2014, p. 1187-1196.

FRANZATO, C.; CELASCHI, F. Processo de metaprojeto para o desenvolvimento estratégico e a inovação das organizações. In: P\&D DESIGN - CONGRESSO BRASILEIRO DE PESQUISA E DESENVOLVIMENTO EM DESIGN, 10., 2012, São Luís. Anais... São Luís: EDUFMA, 2012. p. 114.

GIACCARDI, E. Metadesign as an Emergent Design Culture. Leonardo, v. 38, n. 4, 2005, p. 342-349.

JACOBY, R.; RODRIGUEZ, D. Innovation, growth, and getting to where you want to go. In: LOCKWOOD, T; WALTON, T. (Ed.). Building Design Strategy: Using Design to Achieve Key Bussiness Objectives. New York: Allworth Express, 2008.

JUSTINO, G. Prefeitura entrega à Câmara projeto de regulamentação do Uber. ZH, Porto Alegre. Disponível em: <http://zh.clicrbs.com.br/rs/porto-alegre/noticia/2016/05/prefeituraentrega-a-camara-projeto-de-regulamentacao-do-uber-5802483.html>. Acesso em: 26 jun. 2017.

MAURI, F. Progettare progettando strategia. Milano: Masson S.p.A, 1996.

MERONI, A. Strategic design: where are we now? Reflection around the foundations of a recent discipline. Strategic Design Research Journal, v. 1, n. 1, p. 31-38, 2008.

MORIN, E. Introdução ao pensamento complexo. Porto Alegre: Sulina, 2006.

MURATOVSKI, G. Paradigm Shift: The New Role of Design in Business and Society. She Ji: The Journal of Design, Economics, and Innovation, v. 1, n. 2, p. 118-139, 2015.

NORMANN, R.; RAMÍREZ, R. From Value Chain to Value Constellation: Designing Interactive Strategy. Harvard Business Review, p. 65-77, 1993.

OUDEN, E. Levels of Value. In: Innovation Design: Creating Value for People, Organizations and Society. London: Springer, 2012. p. 13-20.

PARKER, G.; ALSTYNE M.; CHOUDARY S. Platform Revolution: How Networked Markets Are Transforming the Economy And How to Make Them Work for You. New York: W. W. Norton \& Company, Inc., 2016.

TIWANA, A. Platform ecosystems: aligning architecture, governance and strategy. Waltham: Morgan Kaufmann, 2014.

SAMPERE, J. Why Platform Disruption Is So Much Bigger than Product Disruption, 2016. Disponível em: <https://hbr.org/2016/04/why-platform-disruption-is-so-much-biggerthan-product-disruption>. Acesso em: 25 de jun. 2016. 
VASSÃO, C. A. Metadesign: Ferramentas, estratégias e ética para a complexidade. São Paulo: Blucher, 2010.

VERGANTI, R. Design-driven innovation: changing the rules of competition by radically innovating what things mean. Boston: Harvard Business School Publishing, 2009.

ZURLO, F. Design Strategico. In: XXI Secolo, vol. IV, Gli spazi e le arti. Roma: Enciclopedia Treccani. 2010. 